\title{
Remarks on Severity of Trauma Patients Due to Road Traffic Accidents have Been Treated at Vietduc University Hospital Assessed by RTS
}

\author{
Nguyen Duc Chinh ${ }^{1 *}$, Dinh Van Quynh ${ }^{1,2}$ and Vuong Quoc Duc ${ }^{1}$ \\ ${ }^{1}$ Department of Septic surgery and Wound care, Viet Duc University Hospital, Veitnam \\ ${ }^{2}$ Thang Long University, Veitnam
}

*Corresponding author: Nguyen Duc Chinh, Department of Septic surgery and Wound care, Viet Duc University Hospital, Veitnam

\section{ARTICLE INFO}

Received: 慧 October 10, 2021

Published: 幽 October 22, 2021

Citation: Nguyen Duc Chinh, Dinh Van Quynh, Vuong Quoc Duc. Remarks on Severity of Trauma Patients Due to Road Traffic Accidents have Been Treated at Vietduc University Hospital Assessed by RTS. Biomed J Sci \& Tech Res 39(3)-2021. BJSTR. MS.ID.006319.

Keywords: Trauma Scoring; Injury; Prehospital Care for Trauma Patients

Abbreviations: RTS: Revised Trauma Scores; ED: Emergency Department; GCS: Glasgow Coma Scale; T-RTS: T-Revised Trauma Score; ISS: Injury Severity Score; TRISS: Trauma Score-Injury Severity Scores; KTS: Kampala Trauma Score

\begin{abstract}
Purpose: Traffic accidents are always a burden on health care and society, affecting the patients' lives. Revised Trauma Scores (RTS) is a useful tool to predict and assess the risk of mortality, especially for patients admitting to the emergency department. We carried out a study to assess the severity of injuries among trauma patients with traffic accidents at Viet Duc University Hospital.
\end{abstract}

Materials and Methods: A prospective descriptive study was conducted at Viet Duc University Hospital from Dec 2020 to March 2021. All trauma patients related to road traffic accidents, regardless of gender, age, location, or job, completed medical records including deaths were enrolled. The patient was assessed RTS as soon as they arrived at the emergency room. Data were processed using SPSS 20.0 software.

Results: A total of 200 trauma patients due to traffic accidents were enrolled, the age group from 21 to 60 years old accounted for $64 \%$, males accounted for $86.7 \%$. Associated injuries were maxillofacial lesions in $44 \%$, extremities in $23,5 \%$, chest accounted for $22 \%$. The severity of brain trauma with GCS 6 - 8 accounted for the highest rate of $52 \%$. Of them, $42 \%$ were operated on emergency; Outcomes: discharged to die and death at emergency department accounted for $25 \% .98$ patients (49\%) with RTS $\leq$ 9 points, of them, there were 90 patients $(91,8 \%)$ with brain injury. All the dead patients were in this group.

Conclusions and Recommendations: The RTS injury score has a predictive value for the death and survival of trauma patients. The patients who died were in the group with scores $\leq 9$ points. Because it is easy to calculate and suitable for first aid, it is recommended to apply it in clinical practice, especially in the actual conditions of Vietnam today.

\section{Introduction}

Traffic accidents are always a global problem. According to statistics of the World Health Organization - WHO, every year around the world, about 1.35 million people die, leading to 50 million people being permanently disabled due to irreversible injuries, accounting for $30-50 \%$ of total hospital admissions (3). Vietnam is the country with the highest number of traffic accident deaths in
ASEAN and one of the countries with the most traffic accidents in the world. Therefore, traffic accidents are always a current topical issue in Vietnam because it's a burden on health care and society, affecting the patient's lives. Although the Government has been implementing many measures to reduce the number of cases and victims, Vietnam is still in the group of developing countries with high rates of morbidity and mortality caused by traffic accidents 
[1-4]. To improve the qualifications of trauma care, one interesting issue is updating trends in trauma care assessment. Primary trauma care requires assessment of severity to develop appropriate care strategies. The Revised Trauma Score-RTS simplifies the rapid assessment of injury based on Respiratory Rate, Maximum Blood Pressure, and traumatic brain injury severity - Glasgow Coma Scale has been widely recognized for clinical decision making. Several articles have evaluated the performance of RTS in the emergency department (ED) as a triage and prediction tool and showed the effect in clinical practice because bedside assessment tool, each of its variables can be easily and quickly calculated [5,6]. Viet Duc University Hospital, one of the leading centers of surgery in Vietnam, annually receives more than 30.000 trauma patients, most of them are serious trauma patients due to traffic accidents. Quick triage for providing proper treatment is a very important issue for health workers at the ED because it could impact the outcomes of treatment. Therefore, we have conducted this study to evaluate the effectiveness of using RTS on trauma patients at ED of Hospital.

\section{Materials and Methods}

\section{Tool}

In this study, we used the RTS including three parameters are considered for the RTS: maximum systolic blood pressure (MaxSBP, $\mathrm{mm} \mathrm{Hg}$ ), Respiratory Rates (RR, cycles per minute), and Glasgow Coma Scale (GCS). The RTS will range from 0 to 12, where the lower RTS is the more severe injury at the higher risk of death [5] (Table 1).

\section{Table 1.}

\begin{tabular}{|c|c|c|}
\hline Descriptions & Scores & Value \\
\hline \multirow{4}{*}{$\begin{array}{c}\text { Glasgow Coma Scores } \\
\text { (GCS) }\end{array}$} & 3 & 0 \\
\cline { 2 - 3 } & $4-5$ & 1 \\
\cline { 2 - 3 } & $6-8$ & 2 \\
\cline { 2 - 3 } & $9-12$ & 3 \\
\hline \multirow{4}{*}{$\begin{array}{c}\text { Max Blood Pressure } \\
\text { (Max BP) }\end{array}$} & $13-15$ & 4 \\
\cline { 2 - 3 } & 0 & 0 \\
\cline { 2 - 3 } & $1-49$ & 1 \\
\cline { 2 - 3 } & $70-75$ & 2 \\
\hline \multirow{3}{*}{$\begin{array}{c}\text { Respiratory Rates } \\
\text { (RR) }\end{array}$} & 789 & 3 \\
\cline { 2 - 3 } & $1-5$ & 4 \\
\cline { 2 - 3 } & $6-9$ & 0 \\
\cline { 2 - 3 } & $>29$ & 1 \\
\cline { 2 - 3 } & $10-29$ & 3 \\
\hline
\end{tabular}

\section{Setting and Participants}

We prospectively analysed the clinical data of 200 patients with traffic accident acute trauma who were treated in the ED of
Viet Duc University Hospital, a comprehensive tertiary surgical hospital) from December 2020 to March 2021. The patients were assessed the RTS upon admission within the first 24 hours. The data were recorded by attending nurses and doctors at the time of the patient's presentation to the ED. Exclusion criteria were used: The patients already had airway intervention such as endotracheal intubation, mechanical ventilation. The patients died on arrival or were discharged from the ED before termination of emergency treatment, the medical records were not completed.

\section{Data Analysis}

Data were processed using SPSS 20.0 software.

\section{Results}

A total of 200 patients who met the selection criteria were analyzed. The characteristics of subjects are as follows:

*All 50 patients who dead in the group with RTS $\leq 9$. The difference between survival and death rates of groups with RTS $\leq 9$ and RTS $\geq 9$ is statically significant with $\mathrm{P}<0.05$.

\section{Discussion}

Injuries in general and traffic accidents, in particular, are still a global problem. In most developed countries, the injury classification system helps to provide appropriate care strategies, reducing complications and mortality. However, in many developing countries like Vietnam, the trauma emergency system is still incomplete and has many challenges. According to Zhejun Yu [4] each year, more than 400000 people die in China from motor vehicle accidents or industrial accidents, among which 1\%-1.8\% were multiorgan/multisystem injuries. China's regional trauma system hasn't yet been full-fledged, and the management of trauma centers is facing great challenges. Therefore in all emergency rooms, especially in cases of overcrowding and understaffed, it is critical to rapidly screen large numbers of patients, identify the critically ill patients promptly, assess the severity of their condition and assign appropriate treatment priorities, and transfer them towards or intensive care unit are very important issues while treating the patients there [7-9].

In the past 30 years, a different trauma scoring system has been developed, most of the scales are combined with factors related to anatomy and physiology.

However, the scales are too complicated, with many variables, while the emergency needs to be done as quickly as possible. Among the commonly used scales are the Revised Trauma Score (RTS) or the T-Revised Trauma Score (T-RTS), the Severity Scale. Injury - Injury Severity Score (ISS) and Trauma Score-Injury Severity Scores (TRISS), the RTS is widely used. Many studies have evaluated the effectiveness of applying RTS to serve trauma care at 
the ED effectively [10-12]. In 1989 Champion HR [5] has introduced a revised scale to assess the severity of trauma based on three main indicators: Respiratory Rates - Maximum Blood Pressure - Glasgow Coma Scores abbreviated as RTS - Revised Trauma Score. According to the rating scale, the lower the RTS, the higher the risk of death. Because RTS reflects trauma severity, it is considered a useful tool to predict the patient's survival and death. The study of R.A Lichtveld [13] of 503 trauma patients showed that when compared with non-ventilated patients with unchanged RTS, the risk of death in patients with RTS scores was 3.1 times lower $(\mathrm{P}=0.001)$, patients with a good initial RTS score but subsequently intubated were 2.9 times higher $(\mathrm{P}<0.001)$ and in patients with a low RTS, intubated were twice as likely $(\mathrm{P}<0.001)(6)$. According to Nguyen Huu Tu [14] if RTS $\leq 9$ mortality rate is $78.3 \%$ compared to $3.4 \%$ of the RTS group >9 (3). Research results of Nguyen Huu Tu and Nguyen Truong Giang are similar: the higher RTS means the greater rate of survival $[14,15]$. In the study on the effects of T-RTS by Lam Vo Hung [6] to triage of trauma patients at the ED of An Giang hospital in the South of Vietnam in 2012 through 150 trauma patients with traffic accidents. The study has shown that RTS had a statistically significant difference in the mean value of the survival group with the death group with $\mathrm{P}=0.000$. RTS cut-off score $<9$ predicts mortality with a sensitivity of $88 \%$ and a specificity of $99 \%$.

The author recommends that RTS should be widely applied in medical facilities and that the RTS scale is effective in survival prognosis. With a sensitivity of $88.2 \%$ and a specificity of $99.2 \%$, the RTS shows an effective role in assessing the risk of death. The reports of Nguyen Huu Tu, et al. $[14,15]$ also had similar results with sensitivity of $78.7 \%, 76 \%$, and specificity of $95.1 \%$, 84\%. According to the study by Kondo Y et al. [16] about the correlation between long-term mortality and short-term mortality of RTS, T-RTS, TRISS, MGAP (mechanism, GCS, age, and arterial pressure) score, and GAP (GCS, age and arterial pressure) score. They found that T-RTS was better at predicting short-term mortality than long-term mortality. For the aging group, the study of Lam Vo Hung [6] showed that the group with the highest mortality was from 16 to 39 years old, young people who were hyperactive, disregarded traffic rules, and easy to be injured by traffic accidents (accounting for $50 \%$ of the total sample of study). In our series, the age group was the highest proportion from 21 to 60 years old, accounting for 64\%, males accounted for the majority of $86.7 \%$ (Figures $1 \& 2$ ). As for the type of injury, in the study of Lam Vo Hung [6], traumatic brain injury and multiple trauma had a high mortality rate. Among the types of injuries, there was a statistically significant difference in mortality with $\mathrm{P}<0.05$. Nguyen Huu Tu [14] has the same comment as us, the mortality rate due to traumatic brain injury and multiple trauma is $16.6 \%$ and $22.3 \%$, respectively (3).
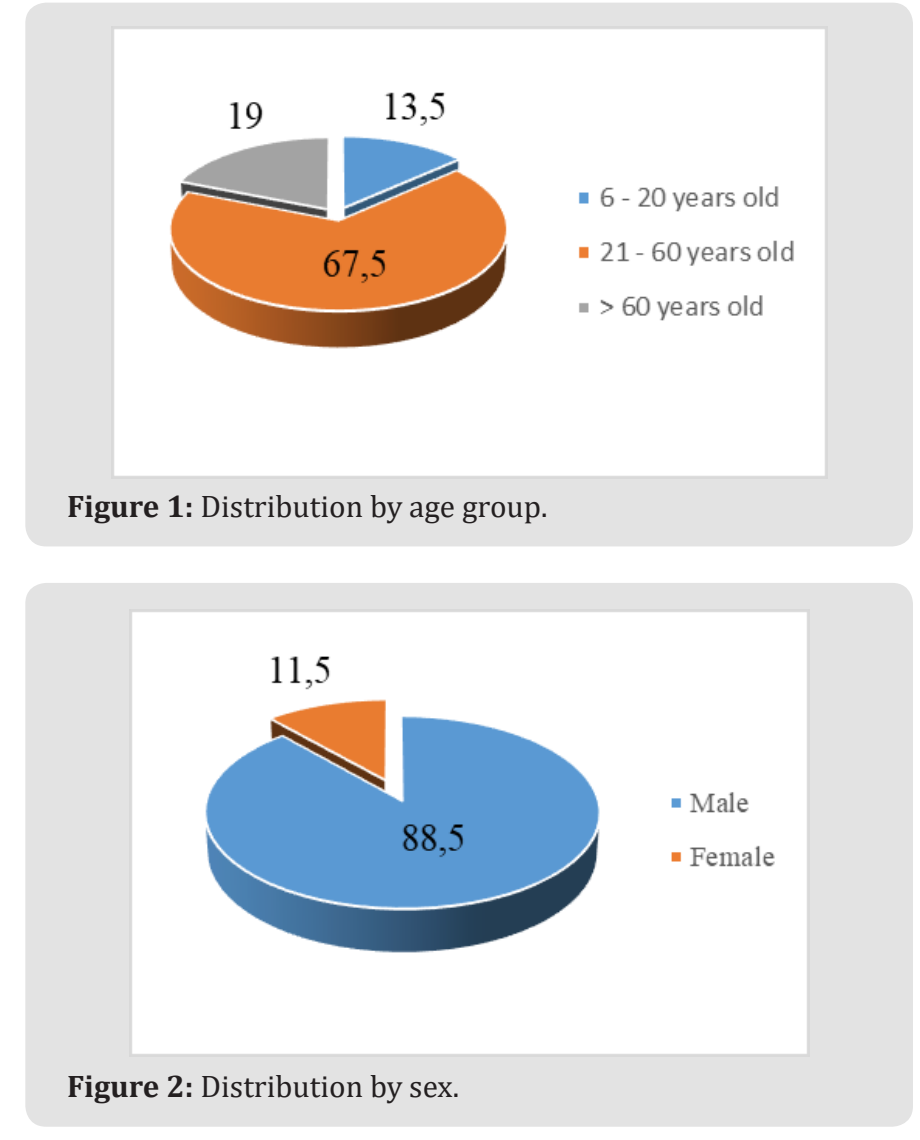

In addition, Nguyen Truong Giang [15] studied 532 accident patients at 103 Hospital and found that the RTS were low in the traumatic brain injury group and the multi-traumatic group. Nguyen Duc Chinh, et al. [17] conducted a study at Viet Duc University Hospital on deaths (2016-2018) showed that the traumatic brain injury group accounted for the highest rate, especially the group with GCS from 6 to 8. Bruno Durante, et al. [18] analyzed 200 patients from December 2013 to February 2014, including trauma victims admitted to the emergency room of the Cajuru University Hospital. The patients were set up in three groups: (G1) penetrating trauma to the abdomen and chest, (G2) blunt trauma to the abdomen and chest, and (G3) traumatic brain injury. The variables we analyzed were: gender, age, day of the week, mechanism of injury, type of transportation, RTS, hospitalization time, and mortality. Regarding mortality, there were $12 \%, 1.35 \%$, and $3.95 \%$ of deaths in G1, G2, and G3, respectively. The median RTS among the deaths was $5.49,7.84$, and 1.16, respectively, for the three groups. The authors concluded that RTS was effective in predicting mortality in traumatic brain injury, however failing to predict it in patients suffering from blunt and penetrating trauma. In our study, the highest proportion of combined injuries were maxillofacial injuries $44 \%$, limb injuries 23.5\%, blunt chest injuries 22\% (Table 2). 
Table 2: Associated lesions $(\mathrm{N}=200)$.

\begin{tabular}{|c|c|c|}
\hline Descriptions & n & \% \\
\hline Blunt abdominal injuries & 20 & 10,0 \\
\hline Blunt chest injury & 44 & 22,0 \\
\hline Spine injury & 21 & 10,5 \\
\hline Maxillo-facial injury & 88 & 44,0 \\
\hline Limb injuries & 47 & 23,5 \\
\hline
\end{tabular}

Patients with severe traumatic brain injury according to the GCS of 6 - 8 accounted for the highest rate of $52 \%$ (Table 3). Up to $40 \%$ were operated on emergency within the first 24 hours. The rate of serious injured was discharged to die at home accounted for $24.5 \%$, $0.5 \%$ died in hospital, overall mortality was $25 \%$ respectively (Table 4). Regarding the RTS in our study, there were mostly in the group of RST at 10 points (50.5\%) and 9 points (35.5\%). There were 98 patients (49\%) with RTS $\leq 9$ (Table 5) of which, $91.8 \%$ with serious brain injury. All 50 fatal and critically ill patients were in this group.

Table 3: GCS, MxBP and RR $(\mathrm{N}=200)$.

\begin{tabular}{|c|c|c|c|}
\hline \multicolumn{2}{|c|}{ Descriptions } & n & $\%$ \\
\hline \multirow{4}{*}{$\begin{array}{c}\text { Max Systolic Blood Pressure } \\
\text { (MxBP)/ mm Hg }\end{array}$} & $0-49$ & 0 & 0 \\
\cline { 2 - 4 } & $\leq 50-75$ & 33 & 16,5 \\
\cline { 2 - 4 } & $9076-89$ & 54 & 27,0 \\
\cline { 2 - 4 } & $>89$ & 113 & 56,5 \\
\hline \multirow{4}{*}{\begin{tabular}{c} 
Glasgow Coma Scores (GCS) \\
\cline { 2 - 3 }
\end{tabular}} & 3 & 0 & 0 \\
\cline { 2 - 4 } & $4-5$ & 53 & 26,5 \\
\cline { 2 - 4 } & $\mathrm{G} \mathrm{6-8}$ & 109 & 54,5 \\
\cline { 2 - 4 } & $\mathrm{G} 9-12$ & 36 & 18,0 \\
\hline \multirow{4}{*}{$\begin{array}{c}\text { Respiratory Rates(RR)/cycle per } \\
\text { minute }\end{array}$} & $0-5$ & 0 & $13-15$ \\
\cline { 2 - 4 } & $\leq 6-9$ & 84 & 42,0 \\
\cline { 2 - 4 } & $>29$ & 8 & 4,0 \\
\cline { 2 - 4 } & $10-29$ & 108 & 54,0 \\
\hline
\end{tabular}

Table 4: Managements and outcomes at ED within first 24 hours $(\mathrm{N}=200)$.

\begin{tabular}{|c|c|c|}
\hline Descriptions & n & \% \\
\hline Operated on emergency & 84 & 42,0 \\
\hline Admitted to hospital & 20 & 10,0 \\
\hline Cared in ICU & 21 & 10,5 \\
\hline Referred to other hospitals & 20 & 10,0 \\
\hline Discharged to die at home & 49 & 24,5 \\
\hline Death & 1 & 0,5 \\
\hline Other & 5 & 2,5 \\
\hline Total & 200 & 100 \\
\hline
\end{tabular}

In a Mega-analysis of Manoochehr S [19], to compare the ability of Revised Trauma Score (RTS) and Kampala Trauma Score (KTS) in Predicting Mortality, the study was conducted by two investigations searched the Web of Science, Embase, and Medline databases and the articles in which the exact number of truepositive, true-negative, false-positive, and false-negative results could be extracted were selected. A total of 11 relevant studies (total $n=20,631$ ) were investigated. Regarding the accuracy and performance, the author concluded that RTS was better than KTS for distinguishing between mortality and survival. Compared with the other researches of domestic and international, we find that RTS is convenient to use in a clinical emergency for trauma victims. Moreover, in addition to the GSC, RTS can also be used as a predictor of severity and mortality, helping physicians at ED to making quick decisions and providing appropriate treatment $[4,6,20,21]$.

Table 5: RTS.

\begin{tabular}{|c|c|c|}
\hline Scores & $\mathbf{n}$ & \% \\
\hline 5 & 1 & 0.5 \\
\hline 6 & 3 & 1.5 \\
\hline 7 & 4 & 2 \\
\hline 8 & 19 & 9.5 \\
\hline 9 & 71 & 35.5 \\
\hline 10 & 101 & 50.5 \\
\hline 12 & 1 & 0.5 \\
\hline Total & 200 & 100 \\
\hline
\end{tabular}

\section{Conclusions}

Through the study of 200 trauma patients due to traffic accidents, we found that RTS has a value in predicting survival as shown by the difference between survived group and the death group. The patients who died were in the group with scores $\leq 9$ statically significant with $\mathrm{P}<0.05$. Because it is easy to calculate and suitable for first aid, it is recommended to apply in clinical practice, especially in the actual conditions of Vietnam. In the difficult conditions of shortage of resources, the trauma emergency system has not been standardized, the application of RTS helps to reduce the morbidity and mortality rate.

\section{Conflict of Interest}

None.

\section{Acknowledge}

The contribution of all staff and colleagues in the Departments of Emergency of Viet Duc University Hospital.

\section{References}

1. (2018) WHO. Global status report on road safety.

2. Tran Thi Ngoc Lan, Luong Mai Anh, Khieu Thi Quynh Trang, Tran Dac Phu (2011) Current death related to road traffic accident in Vietnam. Journal of Practical Medicine 786: 67-70.

3. Nguyen Duc Chin (2013) Situation of emergency care for patients with traffic accident at Viet Duc Hospital 2013. Journal of Practical medicine 931(1): 23-27. 
4. Zhejun Yu, Feng Xu, Du Chen (2011) Predictive value of Modified Early Warning Score (MEWS) and Revised Trauma Score (RTS) for the shortterm prognosis of emergency trauma patients: a retrospective study. BMJ Open 11(3): e041882.

5. Champion HR, WJ Sacco, WS Copes, DS Gann, TA Gennarelli, et al. (1989) A Revion of Trauma Score. J Trauma 29(5): 623- 629.

6. Lam Vo Hung, Tran Van Loi, Vo Van Duc Khoi, Duong Thanh Sang (2012) Value of Revised Trauma Scores (RTS) in predicting survival of patients related to road traffic accident. Year book of scientific conferences in 2012 at An Giang Hospital, pp. 164-171.

7. Gilpin DA, PG Nelson (1991) Revised Trauma Score: a triage tool in the accident and emergency department. Injury 22(1): 35-37.

8. Rocha TFda, Viegas K, Viegas K (2016) Modified early warning score: evaluation of trauma patients. Rev Bras Enferm 69(5): 850-855

9. Salottolo K, Carrick M, Johnson J, Mark Gamber, David Bar Or (2017) A retrospective cohort study of the utility of the modified early warning score for interfacility transfer of patients with traumatic injury. BMJ Open 7(5): e016143.

10. Patel MS, Jones MA, Jiggins M, M Jiggins, SC Williams (2011) Does the use of a "track and trigger" warning system reduce mortality in trauma patients? Injury 42(12): 1455-1459.

11. Subbe CP, Kruger M, Rutherford P, L Gemmel (2001) Validation of a modified early warning score in medical admissions. QJM 94(10): 521526.

12. Oreilly GM, Joshipura M, Cameron PA, Russell Gruen (2013) Trauma registries in developing countries: a review of the published experience. Injury 44(6): 713-721.

13. Lichtveld RA (2008) Triage Revised Trauma Score change between first assessment and arrival at the hospital to predict mortality. Int J Emerg Med 1(1): 21-26.

ISSN: 2574-1241

DOI: 10.26717/BJSTR.2021.39.006319

Nguyen Duc Chinh. Biomed J Sci \& Tech Res (C) $\begin{aligned} & \text { This work is licensed under Creative } \\ & \text { Commons Attribution } 4.0 \text { License }\end{aligned}$

Submission Link: https://biomedres.us/submit-manuscript.php
14. Nguyen Truong Giang (2007) Applying Revised Trauma Score (RTS) to triage and predict patients with multiple trauma. Journal of Practical medicine 6(573): 50- 53.

15. Nguyen Huu Tu (2006) Study on epidemiological characteristics of injured patients on admission, related to injury severity". $13^{\text {th }}$ conferene of Vietnamese Medicine and Pharmacy Universities on Youth Science and Technology, p. 69-75.

16. Kondo Y, Abe T, Kohshi K, Yasuharu Tokuda, E Francis Cook, et al. (2011) Revised trauma scoring system to predict in-hospital mortality in the emergency department: Glasgow coma scale, age, and systolic blood pressure score. Crit Care 15(4): R191.

17. Nguyen Duc Chinh, Tran Tuan Anh, Ngo Thi Hue (2019) Situation of patients who died and were discharged to die due to injuries at Viet Duc Hospital in 2016-2018. Journal of Preventive Medicine 29(8): 135-140.

18. Bruno Durante Alvarez, Danilo Mardegam Razente, Daniel Augusto Mauad Lacerda, Nicole Silveira Lother, Luiz Carlos VON-Bahten, et al. (2016) Analysis of the Revised Trauma Score (RTS) in 200 victims of different trauma mechanisms. Original Article Rev Col Bras Cir 43(05): 334-340.

19. Manoochehry S, Vafabin M, Bitaraf S, Amiri A (2019) A Comparison between the Ability of Revised Trauma Score and Kampala Trauma Score in Predicting Mortality; a Meta-Analysis. Arch Acad Emerg Med Winter 7(1): e6.

20. Kyriacos U, Jelsma J, Jordan S (2011) Monitoring vital signs using early warning scoring systems: a review of the literature. J Nurs Manag 19(3): 311-330.

21. Mary E Moran, Joshua E Nash (2020) Revised Trauma Scale.

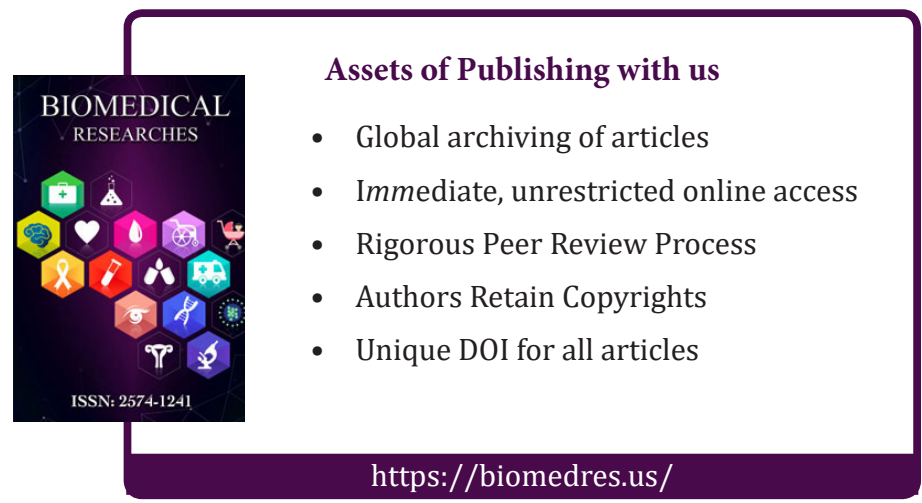

